\title{
Type Classification of Motorized Vehicles Red Light Running and Their Characteristics Analysis
}

\author{
Ya Ping Zhang ${ }^{1}$, Yan Liu ${ }^{1}$, Lan Liư ${ }^{2}$ and Chuan Yun Fu ${ }^{3}$ \\ ${ }^{1}$ School of Transportation Science and Engineering, Harbin Institute of Technology, Harbin, China \\ ${ }^{2}$ School of Safety and Environment Engineering, Hunan Institute of Technology, Hengyang, China \\ ${ }^{3}$ College of Transportation and Logistics, Southwest Jiaotong University, China
}

\begin{abstract}
In order to study types of motorized vehicles red light running and their characteristics, the concept of critical distance was introduced, combining with the start and end of red light, to classify motorized vehicles red light running into three categories: deliberate and unintentional red light violation at red onset and red light violation at red end. Based on video observation data, the number of motorized vehicles that commit any of the afore-mentioned three types of red light violation was statistically analyzed, and then their characteristics under various traffic control and management conditions were explored using $z$-test method. The results show that the majority of red light runners at red start are deliberate, while the unintentional red light violators also share some proportion. At the end of red light, there are a few vehicles violating red light as well. Additionally, the rates of red light running are obviously varying between those three classifications of red light running under the conditions of countdown timer, automatic red light camera, green flashing device, different speed limits and peak period.
\end{abstract}

\section{Introduction}

Red light running is a common traffic violation, but also one main reason to lead to the intersection traffic accident. According to statistics, the traffic accident caused by running a red light accounts for $2.5 \%$ of the total number of intersection accidents[1] and the frequency of this behavior is about one time per every 3.5 minutes[2-3]. An American survey shows that 1.3 times red light running will occur by every 1000 cars going through intersections with the frequency of 3 times every hour[4].Similar research found that the number ranges from 0.45 to 38.5 [5-6]. Running a red light often causes very serious consequences, especially loss of life and property. Therefore, it is of great significance to classify the type of red light running analyzing their characteristics, and put forward the corresponding intervention measures to reduce the occurrence of this behavior.

Predictors of red light running include being under the age of 30 , having poorer driving records, driving smaller and older cars, not wearing a safety belt, getting closer to the vehicle in front, angrily gesturing to other drivers and drinking alcohol prior to the violation[7]. By establishing the matched group, a study of 2015 showed that local, male drivers and passenger vehicles are more likely to run red light and the probability of red light running increases when traffic volume is higher[8]. Lum et al [9]compared the number of red light running vehicle before and after the installation of countdown timer. They found that it reduced by $65 \%$ within the first two months and later gradually restored to the level before the installation. Qian et al [10-11] found that the countdown will give the drivers a signal to accelerate through the intersection with an increase of red light behavior.

Kejun Long et al [12] argued that the countdown could effectively prevent radical acceleration and sudden stop, but could not eliminate the phenomenon of red light running. Helai Huang et al [13] noted that the dilemma zones would cause red light running, which the green signal countdown timer would lead to. Some scholars have studied the influences of red light camera, and different conclusions were made. Retting et al. [14-16] studied the impact of the red light camera, the results showed that red light camera could significantly reduce the rate of red light running. Another study [17] showed that the rate of running a red light had reduced by $69 \%$ in three months of the installation of red light camera and the number was $38 \%$ at the 6th month. While Sze et al [18] think there is no obvious connection between red light running rate and red light camera.

In addition, Yang[19] and other research indicates that, the behaviors of red light running have different characteristics under different traffic flow. Elimitiny et al [20] pointed out that with the increasing of traffic volume, red light running rate would be higher. Morning and evening peak will also increase the red light behavior, working day, the speed limits, vehicle speed on the 
yellow onset and distance to the stop line affected red light running behavior significantly.

Various studies have focused on the behavior of motorized vehicles red light running and their influence factors Little literature has classify the type of red light running at the beginning of red light, and the red light running at red end has not been explored. In view of this, this paper derives and calculates the critical distance based on the observation data, classify the type of red light running and analyzes the characteristics of every type.

\section{Data collection}

\subsection{Study sites}

Seven signal intersections in Harbin city are selected as the video observation sites. The main selection principle of observation sites are excellent sight on the target lanes, no shelter, pedestrian overpass. According to the research purpose of this study, the selection of the intersection should have different signal control scheme, management facilities and speed limit. Table 1 shows the detailed information of the observation sites. For the convenience of records, the following sections of this study use the abbreviation names of each road.
Data collection has been carried out during the period between 1st July to 31st July, 2015. All traffic surveys were carried out during working days of the week (Saturday to Wednesday), during afternoon period (2.00 $\mathrm{pm}$ to $6.00 \mathrm{pm})$. We defined that the first two hours nonpeak hour and the latter two hours peak hour. Every observation site were recorded three days totally. Illustration of video recording is showed as figure 1.

Video observation including the following steps:

(1)Set up the camera on the pedestrian overpass, close to import road in the middle lane, adjust the camera lens and focal length and fixed camera.

(2)Before the shooting, mark 12 pairs of reference points every 10 meters at the entrance lane on both sides from the stop line

(3)After marking the end of the reference point, establish a benchmark at each of the reference points. Record the whole process until the last pair of points.

(4)Turn off the camera after the completion of the steps 3.Start the camera to shoot the traffic flow and traffic signal control on the import road at $2 \mathrm{pm}$.

(5)In the process of shooting, the staff measured and recorded the geometric parameters of the intersection and traffic management facilities, etc.

Through the video recording of seven signal intersections around Harbin urban area for, a total of 84 hours video data were obtained.

\subsection{Video observation}

Table 1. Detailed information of observation sites

\begin{tabular}{|c|c|c|c|c|c|c|}
\hline intersection & Cycle/s & $\begin{array}{c}\text { Yellow } \\
\text { interval/s }\end{array}$ & $\begin{array}{l}\text { Countdown } \\
\text { timer }\end{array}$ & $\begin{array}{l}\text { Red light } \\
\text { camera }\end{array}$ & $\begin{array}{l}\text { Green flash } \\
\text { device }\end{array}$ & Speed $\underset{1}{\operatorname{limit}}(\mathrm{km} \cdot \mathrm{h}$ \\
\hline $\begin{array}{c}\text { ZhengYi Road-XueFu 3rd } \\
\text { Street }\end{array}$ & 111 & 3 & yes & yes & no & 50 \\
\hline $\begin{array}{c}\text { ZhengYi Road-BaoJian } \\
\text { Road }\end{array}$ & 183 & 4 & yes & no & no & 70 \\
\hline $\begin{array}{c}\text { HongQi Street-HuangHe } \\
\text { Road }\end{array}$ & 167 & 4 & yes & yes & no & 60 \\
\hline $\begin{array}{c}\text { XianFeng Road-HongQi } \\
\text { Street }\end{array}$ & 161 & 4 & yes & no & no & 60 \\
\hline $\begin{array}{c}\text { ZhongShan Road-GeXin } \\
\text { Street }\end{array}$ & 142 & 3 & yes & yes & no & 60 \\
\hline $\begin{array}{c}\text { DaXin Street-GongYu } \\
\text { Street }\end{array}$ & 119 & 3 & no & yes & no & 60 \\
\hline $\begin{array}{c}\text { HuangHe Road-HuaShan } \\
\text { Road }\end{array}$ & 177 & 3 & no & yes & yes & 50 \\
\hline
\end{tabular}

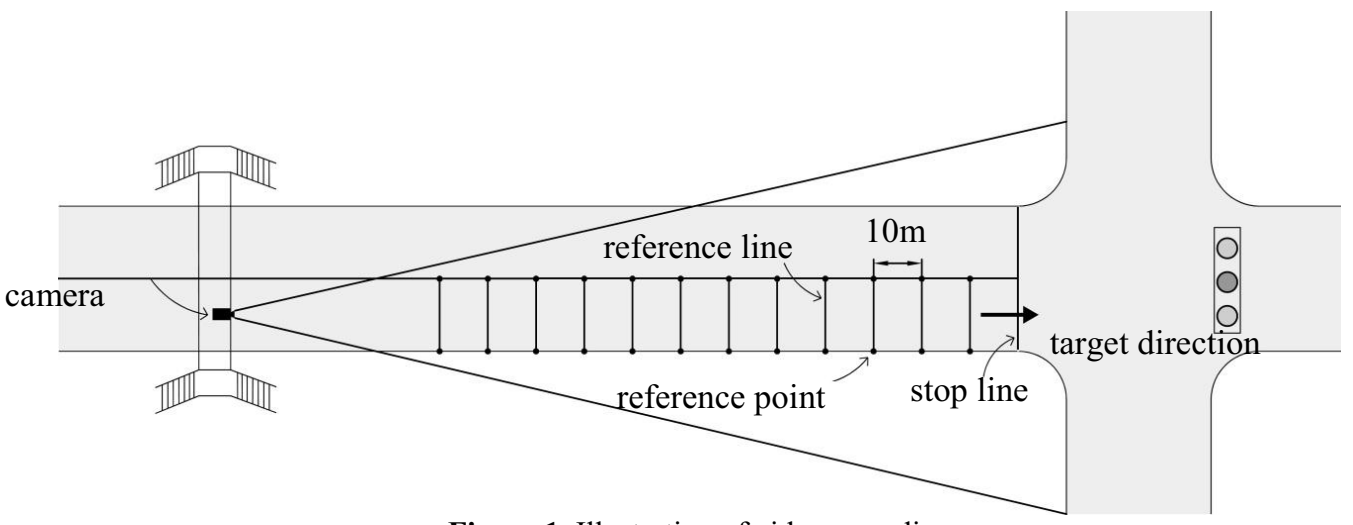

Figure 1. Illustration of video recording 


\subsection{Data extraction}

Use Potplayer to play the video data, draw the reference lines in the video on the screen with the drawing software. Then play the video of the yellow light duration and red start and red end period frame by frame. Data extracted include: moment of turning to yellow light, distance between target car to stop line on the yellow onset, distance between rear wheel of target car to upstream recent reference line on yellow onset, vehicle type, time headway, moment of braking lights turning on and the number of red light running at red end, etc.

In this article, target vehicle means the first stop vehicle during the yellow light, vehicles running yellow light running red light at both red onset and offset. After data extraction, exclude some useless data including the incomplete data caused by the bad observation sight. Data that driver's perception reaction time is negative should be eliminated as well. Table 2 shows the sample size at each observation site.

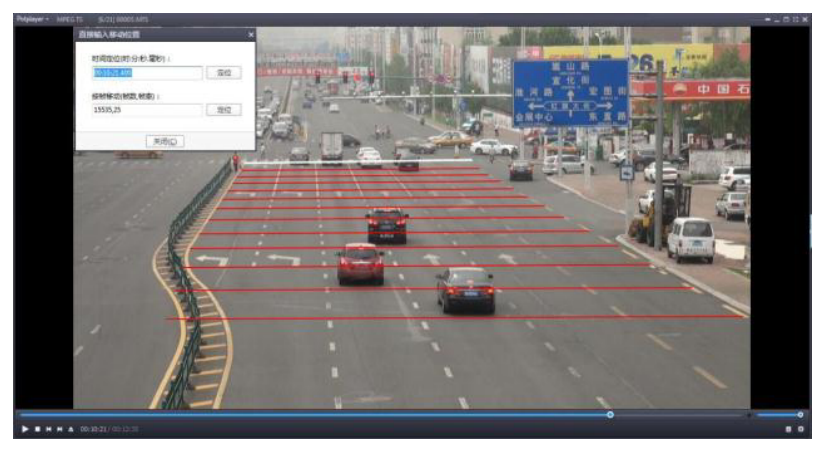

Figure 2. Scenes for data collection

Table 2. Sample size at each observation site

\begin{tabular}{|c|c|c|c|}
\hline intersection & $\begin{array}{c}\text { First-stop-car at } \\
\text { yellow light }\end{array}$ & $\begin{array}{c}\text { Running yellow } \\
\text { light }\end{array}$ & $\begin{array}{c}\text { Running red } \\
\text { light }\end{array}$ \\
\hline ZYXF & 90 & 351 & 37 \\
\hline ZYBJ & 86 & 159 & 40 \\
\hline HQHH & 216 & 378 & 68 \\
\hline XFHQ & 168 & 371 & 36 \\
\hline ZSGX & 265 & 324 & 21 \\
\hline DXGY & 133 & 275 & 46 \\
\hline HHHS & 278 & 474 & 77 \\
\hline $\begin{array}{l}\text { Number of } \\
\text { observation }\end{array}$ & 1236 & 2332 & 325 \\
\hline
\end{tabular}

Usually case, during the red light, the red light behavior occurs very rarely, in the process of video observations also found no the behavior. Therefore, the statistics of vehicle running the red light include the red onset and red offset. This study only focuses on this two conditions.

\section{Type classification of motorized vehicles red light running}

\subsection{Critical distance}

In this paper, the critical distance is used as the criterion for the classification of the behavior type of the vehicle running red light. We assume that there exists a critical distance (d) perceived by a normal driver at each intersection when noticing the beginning of a yellow phase.[21]. Drawing on the ideas of literature [21], the derivation of critical distance is as follows:

Logit model is applied to analyze the decision of driver's driving behavior, that is, choose to continue driving or stopping at the yellow onset. Driving behavior decision is a binary dependent variable $\mathrm{y},{ }^{y=1}$ means the choice of continue to drive, $y=0$ means the choice of stopping. Independent variables include two continuous variables and four discrete variables.

Driving behavior decision is a binary dependent variable y, $y=1$ means the choice of continue to drive, $y=0$ means the choice of stopping. Independent variables include two continuous variables and four discrete variables. Continuous variables refers to the distance of the vehicle to stop line on the yellow onset $x_{1}$ and the corresponding speed ${ }^{x_{2}}$, the discrete variables refers to the countdown timer ${ }^{x_{3}}$, the camera ${ }^{x_{4}}$, green flash device $x_{5}$, and peak time $x_{6}$. Among them, countdown positive $x_{3}=1$, countdown negative $x_{3}=0$, similar to $x_{4}$ and $x_{5}$, peak period $x_{6}=1$, non- peak period $x_{6}=0$

Then, the binary dependent Logit model is as follows:

$$
\log i t\left(P_{y=1}\right)=\ln \left(\frac{P_{y=1}}{1-P_{y=1}}\right)=\alpha+\beta_{1} x_{1}+\beta_{2} x_{2}+\beta_{3} x_{3}+\beta_{4} x_{4}+\beta_{5} x_{5}+\beta_{6} x_{6}
$$

where

$$
\begin{array}{ll}
P_{y=1} & \begin{array}{l}
\text { probability of continue to drive } \\
\log i t\left(P_{y=1}\right)
\end{array} \\
\begin{array}{l}
\text { logarithm of probability of } \\
\text { continue to drive and stop } \\
\text { constant }
\end{array} \\
\beta_{1}, \beta_{2}, \ldots, \beta_{6} & \text { coefficient }
\end{array}
$$

Match the observation data using $\mathrm{R}$ and calibrate model parameters. The results show that only the two continuous variables significantly affect red light violation statistically significant at the $5 \%$ level. Furthermore, the speed at the yellow onset is a function of distance, it can be implied that the distance from the target car to the stop line at the yellow onset is major factor that affect diver's driving decision to pass or stop. Therefore, Eq.(1) becomes:

$$
\log i t\left(P_{y=1}\right)=\ln \left(\frac{P_{y=1}}{1-P_{y=1}}\right)=\alpha+\beta x
$$

where

$x$ distance from the target car to the stop line at the yellow onset

Change the form to the probability of driving choice:

$$
P_{y=1}=\frac{1}{1+e^{\alpha+\beta x}}
$$


Now, to derive the critical distance to the stop line, $\mathrm{d}$, for a driver either to clear the intersection or to make a stop, we can consider $P_{y=1}$ as a statistical density function for a random variable, $D$. Then, the critical distance to the stop line is defined as the median of this random variable, $D$, that is, $d$ is the value of $D$, for which

$$
\int_{0}^{d} P_{y=1} d x=0.5
$$

Finally, the parameters are estimated by a maximum likelihood technique with the likelihood function:

$L(\alpha, \beta)=\sum_{d=1}^{n}\left[\ln \left(\frac{1}{1+e^{\alpha+\beta x_{d}}}\right)+\alpha+\alpha y_{d}+\beta x_{d}-\beta x_{d} y_{d}\right]$

where $y_{d}=1$ if a driver accepted a distance to pass and 0 if a driver rejected a distance to make a stop, $\mathrm{n}=$ number of observed decisions (pass or stop), and $x_{d}=$ a vehicle's distance to the stop line when the yellow phase starts.

The maximization of $L(\alpha, \beta)$ reveals values for $\alpha$ and $\beta$ in Eq.(3). Since this is the distribution function of a logistic distribution, Eq.(4) can be solved for $\mathrm{d}$ as the mean of this distribution, which is: $d=\frac{\alpha}{\beta}$

\subsection{Type of red light running}

Calculate each critical distance of intersection with the method of 2.1 based on the observation data. We can classify the red light running at red onset into two types:

(1) Deliberate red light running: passing the intersection if the current location to the stop line at the start of yellow phase is longer than the critical distance
(2) Unintentional red light running: passing the intersection if the current location to the stop line at the start of yellow phase is less than or equal to the critical distance

In addition, red light running at the red end has been researched in this study.

(1)Red light onset

According to the critical distance, the statistical results of red light running vehicle are as table 3 . As shown in table 3 , the critical distance ranges from $30 \mathrm{~m}$ to $60 \mathrm{~m}$ and the majority are at the range of $40 \mathrm{~m}$ to $50 \mathrm{~m}$. As far as the number is concerned, deliberate red light running is higher than unintentional red light running. It is worth noting that the total violation at the ZSGX intersection were deliberate red light running, however, the deliberate red light violation is less than the unintentional violation at the ZYXF intersection.

Thus it can be seen that the majority of red light runners at red start are deliberate, while the unintentional red light violators also share some proportion. Short yellow duration, the dilemma zone and drivers' distraction may cause some unintentional red light running.

(2)Red light end

Table 4 shows the statistical results of red light running vehicles at red end. It indicates that this type of red light running occurred a little during the observation period. Among all of the observations, it scarcely happened at ZYXF, DXGY and HHHS intersection. It can be seen that red light running at the red end is less than the red light running at the red onset comparing the results in table 3 and table 4 . Some time is needed to start a car at the red light end from steady to activation. On the contrary, it is easier for a car at the red light onset to run a red light.

Table 3. Statistics of red light running vehicles at red onset

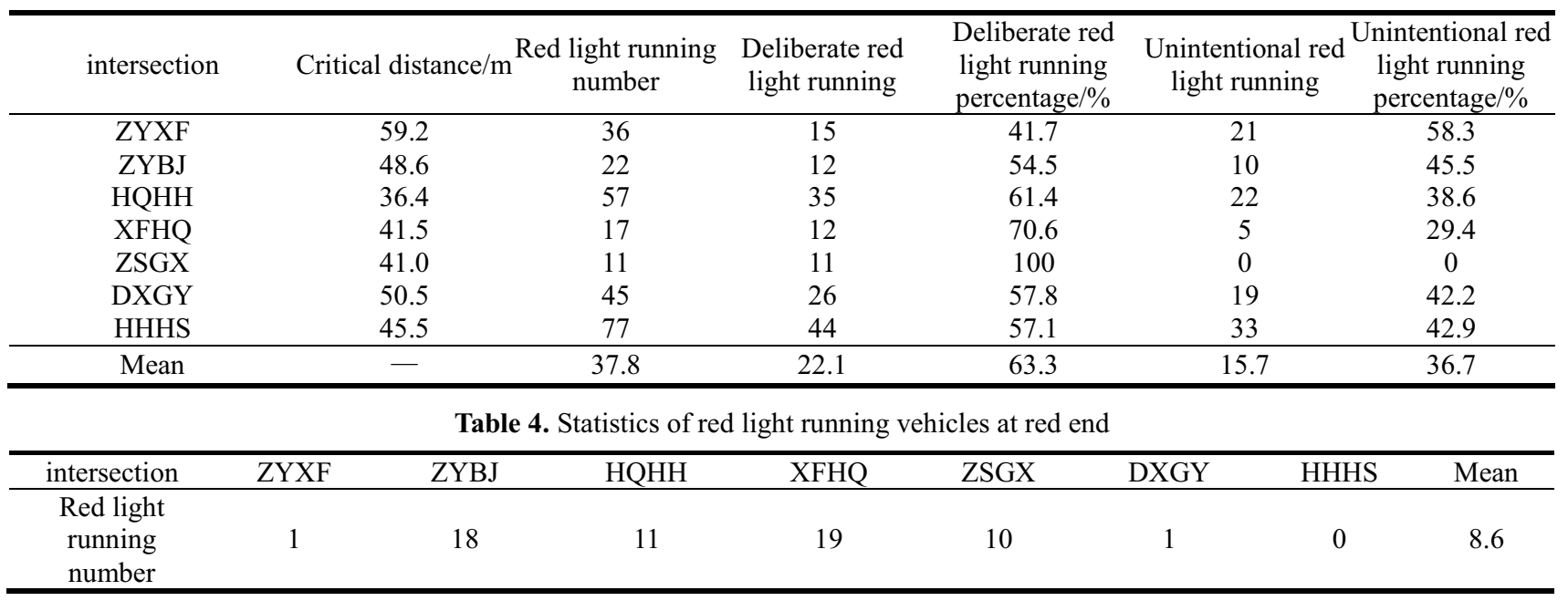

\section{Red light running characteristics analysis}

\subsection{Method}

It is difficult to compare the characteristics of every type of red light running under different conditions using the red light running rate only. Hence, $Z$ test is employed for the significance analysis of red light running rate. The method of $\mathrm{Z}$ test is as follows:

$$
Z_{\text {stat }}=\frac{p_{1}-p_{2}}{\sqrt{p(1-p)} \sqrt{\frac{1}{Q_{1}}+\frac{1}{Q_{2}}}}
$$


Where, $p_{1}=\frac{N_{1}}{Q_{1}}, p_{2}=\frac{N_{2}}{Q_{2}}, p=\frac{N_{1}+N_{2}}{Q_{1}+Q_{2}}$.

$Z_{\text {stat }} \quad Z$ value

$p_{1}, p_{2}$

Red light running rate

$N_{1}, N_{2}$

$Q_{1}, Q_{2}$

Number of red light running

Traffic volume

The critical value of $Z$ test at $95 \%$ confidence level is \pm 1.96 , which means that it is significant statistically when $Z_{\text {stat }}>1.96$ or $Z_{\text {stat }}<-1.96$.

\subsection{Countdown timer}

Divide the intersections based on having countdown timer or not, calculate the red light running rate of three classifications, respectively. Take the deliberate red light running as example, calculate $Z$ value under with and without countdown timer condition.

$$
\begin{aligned}
& p_{1}=\frac{69}{43858}=1.573 \times 10^{-3} \quad p_{2}=\frac{85}{132394}=6.420 \times 10^{-4} \\
& p=\frac{69+85}{43858+132394}=8.737 \times 10^{-4} \quad Z_{\text {stat }}=5.72
\end{aligned}
$$

Similarly, calculate the $Z$ value of unintentional behavior and the one at the red end. Table 5 shows the results under different conditions.

$\mathrm{Z}$ test results indicate that countdown timer is significant variable for three red light running, which means that the countdown timer affect red light running behavior significantly. In terms of the red light running rate, the 2 types of red light running at red light onset are significantly less than the no countdown condition, while the red light end is opposite. This shows that the countdown timer can effectively reduce the red light running at the red onset, but to a certain extent, will increase the rate at the end of the red light.

Table 5. Results of z-test for red light running rate under with

\begin{tabular}{|c|c|c|c|c|}
\hline \multirow{2}{*}{\multicolumn{2}{|c|}{ Red light running type }} & \multicolumn{2}{|c|}{ Red onset } & \multirow{2}{*}{$\begin{array}{c}\text { Red } \\
\text { end } \\
\text { running } \\
\text { rate } / \% 0\end{array}$} \\
\hline & & $\begin{array}{c}\text { deliberate } \\
\text { rate } / \% 0\end{array}$ & $\begin{array}{l}\text { unintentional } \\
\text { rate } / \% 0\end{array}$ & \\
\hline \multirow[t]{2}{*}{ condition } & $\begin{array}{c}\text { No } \\
\text { countdown } \\
\text { timer }\end{array}$ & 1.57 & 1.19 & 0.02 \\
\hline & $\begin{array}{l}\text { Countdown } \\
\text { timer }\end{array}$ & 0.64 & 0.44 & 0.45 \\
\hline \multicolumn{2}{|c|}{$\mathrm{Z}$ value } & 5.72 & 5.43 & -4.16 \\
\hline \multicolumn{2}{|c|}{ significance } & $\sqrt{ }$ & $\sqrt{ }$ & $\sqrt{ }$ \\
\hline
\end{tabular}
and without countdown timer conditions

\subsection{Red light camera}

Divide the intersections based on having red light camera or not, calculate the red light running rate of three classifications, respectively. Z-test results are as showed in table 6 .
Table 6 shows that under red light camera, the red light running rates at red light onset are higher than the ones without red light camera. But deliberate running a red light rate does not have statistical significance. It means that red light camera has no significant effect on deliberate red light running on the red onset and the unintentional red light running will be affected by the device. In addition, there is significant difference on the red light running rate under with and without red light camera. And the rate under no camera condition is higher than the one when the camera exists. The results show that red light camera can reduce the red light violation on the red end and increase the unintentional red light running. But it has no significant effect on the deliberate red light running.

Table 6. Results of z-test for red light running rate under with

\begin{tabular}{|c|c|c|c|c|}
\hline \multirow{2}{*}{\multicolumn{2}{|c|}{$\begin{array}{l}\text { Red light running } \\
\text { type }\end{array}$}} & \multicolumn{2}{|c|}{ Red onset } & \multirow{2}{*}{$\begin{array}{l}\text { Red end } \\
\text { running } \\
\text { rate } / \% \text { o }\end{array}$} \\
\hline & & $\begin{array}{c}\text { deliberate } \\
\text { rate } \% \%\end{array}$ & $\begin{array}{l}\text { unintentional } \\
\text { rate/\%o }\end{array}$ & \\
\hline \multirow{2}{*}{ condition } & $\begin{array}{l}\text { No red } \\
\text { light } \\
\text { camera }\end{array}$ & 0.62 & 0.39 & 0.96 \\
\hline & $\begin{array}{c}\text { red } \\
\text { light } \\
\text { camera }\end{array}$ & 0.95 & 0.69 & 0.17 \\
\hline \multicolumn{2}{|c|}{$\mathrm{Z}$ value } & -1.91 & -2.11 & 7.43 \\
\hline \multicolumn{2}{|c|}{ significance } & $x$ & $\sqrt{ }$ & $\sqrt{ }$ \\
\hline
\end{tabular}
and without automatic red light camera conditions

\subsection{Green flash device}

Divide the intersections based on having green flash device or not, calculate the red light running rate of three classifications, respectively. Z-test results are as showed in Table 7.

Table 7 shows that there is a significant difference under with and without green flash device conditions, which indicates that green flash device affect the behavior of the red light significantly. Under green flash condition, red light running rate at red onset is higher than the ones without the device, and the influence at the end of the red light is contrary. The results indicate that green flash easily lead to the occurrence of running a red light when turning to red light, but can effectively reduce violation at the end of red period.

Table 7. Results of z-test for red light running rate under with and without green flash device conditions

\begin{tabular}{cccc}
\hline \multirow{2}{*}{$\begin{array}{c}\text { Red light running } \\
\text { type }\end{array}$} & \multicolumn{2}{c}{ Red onset } & $\begin{array}{c}\text { Red end } \\
\text { running } \\
\text { rate/\%o }\end{array}$ \\
\cline { 2 - 3 } condition & $\begin{array}{c}\text { deliberate } \\
\text { rate/\%o }\end{array}$ & $\begin{array}{c}\text { unintentional } \\
\text { rate/\%o }\end{array}$ & \\
$\begin{array}{c}\text { No } \\
\text { green } \\
\text { flash } \\
\text { device } \\
\text { green } \\
\text { flash } \\
\text { device }\end{array}$ & 0.72 & 0.50 & 0.39 \\
\hline Z value & 1.96 & 1.51 & 0 \\
\hline significance & -5.83 & -5.59 & 2.92 \\
\hline
\end{tabular}




\subsection{Speed limit}

There were three different limit speed at the observation sites, $50 \mathrm{~km} / \mathrm{h}, 60 \mathrm{~km} / \mathrm{h}$ and $70 \mathrm{~km} / \mathrm{h}$. Table 8 shows the red light running rate under different speed limit. Z-test results are as showed in Table 9.

Table 8. Red light running rate under different speed limits

\begin{tabular}{|c|c|c|c|c|}
\hline \multirow{2}{*}{\multicolumn{2}{|c|}{$\begin{array}{l}\text { Red light } \\
\text { running type }\end{array}$}} & \multicolumn{2}{|c|}{ Red onset } & \multirow{2}{*}{$\begin{array}{c}\text { Red end } \\
\text { running rate } \\
1 \%\end{array}$} \\
\hline & & $\begin{array}{c}\text { deliberate } \\
\text { rate } / \%\end{array}$ & $\begin{array}{l}\text { unintentional } \\
\text { rate } / \% \%\end{array}$ & \\
\hline \multirow{3}{*}{$\begin{array}{c}\text { Limit } \\
\text { speed/ } \\
\left(\mathrm{km} \cdot \mathrm{h}^{-}\right. \\
\left.{ }^{-}\right)\end{array}$} & 50 & 0.96 & 0.87 & 0.02 \\
\hline & 60 & 0.90 & 0.50 & 0.44 \\
\hline & 70 & 0.56 & 0.46 & 0.83 \\
\hline
\end{tabular}

Table 9. Results of z-test for red light running rate under different speed limits

\begin{tabular}{cccc}
\hline \multirow{2}{*}{$\begin{array}{c}\text { Compared } \\
\text { condition }\end{array}$} & $\begin{array}{c}\text { deliberate } \\
\text { red light } \\
\text { running }\end{array}$ & $\begin{array}{c}\text { unintentional } \\
\text { red light } \\
\text { running }\end{array}$ & $\begin{array}{c}\text { red light } \\
\text { running at } \\
\text { red end }\end{array}$ \\
\hline $50 \mathrm{~km} / \mathrm{h}-60$ & $0.33(\times)$ & $2.88(\sqrt{ })$ & $\begin{array}{c}-4.97 \\
(\sqrt{ })\end{array}$ \\
$\mathrm{km} / \mathrm{h}$ & $1.60(\times)$ & $0.19(\times)$ & $\begin{array}{c}-2.28 \\
(\sqrt{ })\end{array}$ \\
$60 \mathrm{~km} / \mathrm{h}-70$ & & $1.88(\times)$ & $\begin{array}{c}-6.84 \\
(\sqrt{ })\end{array}$ \\
$\begin{array}{c}50 \mathrm{~km} / \mathrm{h} / \mathrm{h}-70 \\
\mathrm{~km} / \mathrm{h}\end{array}$ & $1.74(\times)$ & & \\
\hline
\end{tabular}

From table 8 we can see that red light running rate at the red onset decreases with the increase of the speed limit. and it has an opposite effect at the red end. However, $\mathrm{z}$ test results shows that there are no significant difference of deliberately running red light under different limit speed. The unintentional red light running rate under $60 \mathrm{~km} / \mathrm{h}$ is less than the rate under $50 \mathrm{~km} / \mathrm{h}$, and there are significant difference of red light running rate at red end under different limit speed. The above results indicate that the speed limit value has no effect on the behavior of running a red light at the red light onset, and the increase of the speed limit will significantly increase the occurrence of red light running at the end of the red signal.

\subsection{Peak period}

Calculate the red light running rate of three classifications under peak and non-peak period, respectively. Z-test results are as showed in table 10 .

Table 10. Results of z-test for red light running rate under different periods

\begin{tabular}{cccc}
\hline \multirow{2}{*}{$\begin{array}{c}\text { Red light running } \\
\text { type }\end{array}$} & \multicolumn{2}{c}{ Red onset } & $\begin{array}{c}\text { Red end } \\
\text { running } \\
\text { rate/\%o }\end{array}$ \\
\cline { 2 - 3 } $\begin{array}{c}\text { deliberate } \\
\text { rate/\%o }\end{array}$ & $\begin{array}{c}\text { unintentional } \\
\text { rate }\end{array}$ & 0.38 \\
$\begin{array}{c}\text { Non- } \\
\text { peak } \\
\text { condition } \\
\text { period } \\
\text { Peak } \\
\text { period }\end{array}$ & 0.94 & 0.65 & 0.30 \\
\hline Z value & 0.86 & 0.60 & 1.02 \\
\hline significance & $\times$ & 0.36 & $\times$ \\
\hline
\end{tabular}

From table 10, we can see that the red light running rates under non-peak period are greater than the peak period But from the $Z$ test results, this difference is not significant statistically. Therefore, peak hour can not affect the red light running behavior significantly.

\section{Conclusions}

Motorized vehicles red light running is one of the important causes for frequent traffic accidents at signalized intersection. This study classified the type of red light running according to red start and red end based on the video. Based on the critical distance, red light running was divided into three types combined with the red start and red end: deliberate and unintentional red light violation at red onset and red light violation at red end.

Video observation and statistics found that, majority of red light runners at red start are deliberate(63.3\%), while the unintentional red light violators also share some proportion $(36.7 \%)$. The video observation also showed that drivers would run a red light at red end but significantly less than the number of running a red light at red onset.

Through the analysis of the characteristics of the red light running under different conditions, it can be seen that the influence of different traffic control and management measures on the behavior of red light is different. Countdown timer reduces red light violation at red onset, but the green flash device produces the opposite effect. Red light camera increases unintentional red light violation at red onset but has no significant effect on deliberate behavior. Raising speed limit has no significant effect both on deliberate and unintentional red light violation at red onset. Running a red light at the red end will be decreased significantly under red light camera and green flash device conditions. But the countdown timer and higher speed limit will produce the opposite effect. The three types of red light running will not be influenced significantly by the peak hour.

It is necessary to explain that the results of this study are based on a small sample size because of the experimental conditions, time and other restrictions. Further research will expand the scope of investigation and extend the survey time at same signal intersection.

\section{Acknowledgments}

This paper is supported by Open Project of Key Laboratory of Ministry of Public Security for Road Traffic Safety, China (2015ZDSYSKFKT06-1).

\section{References}

1. QIU Chen-lu, XU Hui-ying, SHAO Zhi-hua, TANG Li-hu. China Pub Sec 34,84-87(2014)

2. Mohamedshah Y M, Chen L W, Council F M. Report No. FHWA RD-00-112, FHWA, DOT, U.S., (2000).

3. Milazzo J S, Hummer J E, Prothe L M. Ins Transp Res Edu, NCSU, U.S., (2001). 
4. Retting R A, Williams A, Greene M. Transportation Res Rec, 1640,23-26 (1998).

5. Kamyab A, McDonald T, Stribiak J. Center Transp Res Edu, ISU, U.S., (2000).

6. Retting R A, Greene M., Transportation Res Rec 1-7 (1997).

7. Retting R A, Williams A F. J Safety Res, 27,9-15 (1996)

8. WANG Xue-song, LI Jia, ZHONG Chu-jun. Urb Trans of China, 13, 73-79 (2015).

9. Lum K M, Harun H. Journal of Transportation Res F, 9 29-41 (2006)

10. QIAN Hong-bo, HAN Hao. China Safety Sci J, 20 9-13 (2010)

11. CAO Yi, YANG Zhong-zhen, ZUO Zhong-yi. China Safety Sci J, 25 77-82 (2015)

12. Long K, Liu Y, Han L D. Safety Sci, 54 8-16 (2013)
13. Huang H L, Wang D, Zheng L, Li XiaoQi. Acc Ana Prev, 71 248-260 (2014)

14. Retting R A, Ferguson S A, Hakkert A S. Traffic Inj Pre, 4 17-23 (2003)

15. Porter B E, Johnson K L, Bland J F. Acc Ana Prev, 50 1104-1111 (2013)

16. McCartt A T, Hu W. J Safety Res, 48 57-62 (2014)

17. Chen P L, Pai C W, Jou R C, Wafaa Saleh, Ming-Shin Kuo, Acc Ana Prev, 75 128-136 (2015)

18. Sze N N, Wong S C, Pei X, Choi, Y.K.Lo. Acc Ana Prev, 43 265-271 (2011)

19. Yang C Y D, Najm W G. J Safety Res, 38 311-321 (2007)

20. Elmitiny N, Yan X D, Radwan E, Acc Ana Prev, 42 101$111(2010)$

21. Liu Y, Chang G L, Yu J. J Transp Eng, 138 31-42 (2011) 